\title{
Development of Interactive Learning Media for Simulating Human Digestive System
}

\author{
Kristo Radion Purba, Liliana, Daniel Runtulalu \\ Department of Informatics \\ Petra Christian University \\ Surabaya, Indonesia \\ kristo@petra.ac.id, lilian@petra.ac.id, danielruntulalu@gmail.com
}

\begin{abstract}
The learning process can be done by utilizing multiple media, such as sounds, images, and animation. In general, the available learning media only use one medium that is either images or texts. Combining some elements of these mediums will complement each other. In this research, an interactive learning media application for digestive system will be created. There are 3 topics in this application, i.e. illness, digestive system, and test. The simulation was made interactive, with interactivities such as hover, click and drag with the mouse, and type using keyboard. The test menu contains multiple choice and hangman. This application was created with Adobe Flash CS6 and ActionScript 3 as the programming language. This application is tested to several users using questionnaire. Based on the results of the survey, memory and subjective satisfaction has a $85 \%$ of score because of easyness of use and easy navigation. A hurried user often had difficulties in doing the test because they didn't read the instructions given.
\end{abstract}

Keywords-Interactive media; media for learning; digestive system; simulation.

\section{INTRODUCTION}

Learning media with the static texts and images is usually a boring process. Continuous reading without any other supporting media will be boring. Additional dynamic and interactive media is needed to learn such an a complex materials that combines images, sounds, and animations into one. Interactive media can certainly help the learning process better.

Learning digestive system is usually done by using books that contain only text and images. Digestion process inside human body can be easily explained using animations, which is can't be provided by books, thus learning process can become more interesting. It is expected that the students can understand the digestive process from mouth to large intestine and diseases of the digestive system more efficiently.

\section{LITERATURE REVIEW}

\section{A. Human Digestive System}

Digestion of food is the process of converting foods from large sizes into smaller and delicate sizes, as well as breaking down complex food molecules into simple molecules using enzymes and digestive organs [1].

The process of digestion of food occurs physically and chemically, so that the digestion of food is distinguished from the digestion of mechanical and chemical digestion. Mechanical digestion is the process of destroying and milling food physically into small pieces. The process of absorption of food particles by the body with the help of digestive enzymes is called chemical digestion.

\section{B. Digestive Organs}

1) Oral cavity

Inside the oral cavity there are several digestive tools namely the teeth, tongue, and salivary glands. Mechanical digestion occurs in the oral cavity when food is converted into bolus. [2]

2) The esophagus

The esophagus is the connecting channel between the mouth and the stomach. Through the esophagus food is pushed into the stomach with peristaltic motion. Food takes only 6 seconds to get into the stomach from the mouth.

\section{3) Stomach}

The stomach is located inside the upper abdominal cavity under the diaphragm. The stomach has an elastic wall, so it can store food with a capacity of 2 - 4 liters. The food is digested in the stomach approximately 6 hours, after that leaves the stomach into the small intestine.

\section{4) Small intestine}

The small intestine is a place of chemical digestion and the absorption of food substances. The food that enters the small intestine mixes with the enzymes produced from the liver and pancreas.

\section{5) Large intestine}

Water and undigested food further into the digestive tract of food called the large intestine. The main function of the large intestine is to absorb water that still exists in the digestive tract. The last part of the large intestine is called a rectum about $12 \mathrm{~cm}$ long and ends with anus. Anus is the ultimate hole of the gastrointestinal tract as a stool dump.

\section{Learning Media}

Learning media is an intermediary or a tool that connects between teachers and learners. Learning media is also everything that can be used to stimulate the thoughts, 
feelings, emotions, attention, skills and skills of a person so as to encourage the learning process either one way or more. Because the learning process uses the media as a process of interaction, then the learning media occupies an important position as one component in learning.

Without a media, a learning can not proceed well and effectively. The purpose of learning with media is as follows [3]:

- Improve learning experience

- Gives a creative way of motivating new learners

- $\quad$ Support learning by offering differentiated learning

- Provides individualized learning experience, while increasing the potential audience.

\section{Simulation Model}

The simulation model is basically one of the learning strategies that aims to provide concrete experience through the creation of copies of experiences that are close to the atmosphere of near-real experience and take place in an atmosphere without risk.

Simulations may represent something too large or too complex to carry in the classroom [4]. For example, if studying a human digestive system, it would be very inconvenient to show directly the process of digestion of food along with the digestive organs. If using a video that can be played in a computer, then the learning process can be easier, but it also can avoid the smell of organs that are uncomfortable and disgusting.

\section{SySTEM DESIGN AND IMPLEMENTATION}

The application is consisting of 3 parts, i.e. digestive simulation, digestive disease, and test. This paper will only discuss about the simulation part, as it is the main part. The digestive disease only contains information in text, and the test will be multiple choice question.

The simulation menu consists of 7 body parts from mouth to anus, simulating the process of digestion. The digestive disease menu contains information, symptom and prevention of ulcer and diarrhea. The test menu contains multiple choice questions regarding the materials. The main menu interface can be seen in Fig.1.

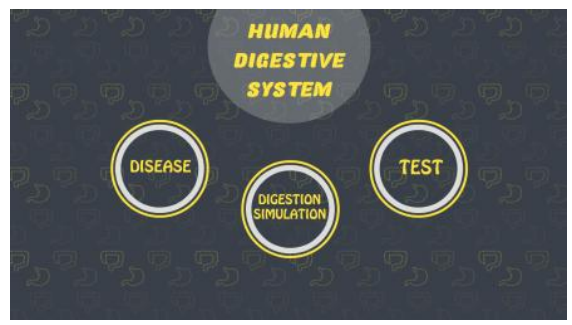

Figure 1. Main menu

\section{A. Digestive Simulation}

In this chapter, the digestive process will be simulated from mouth to anus, and user cannot skip the process. The flow is as follows:

\section{1) Teeth}

There are 2 digestive process in teeth, i.e. mechanical digestion and chemical digestion. The process can be seen in Fig. 2.

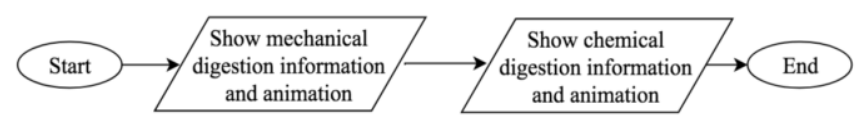

Figure 2. Process of teeth simulation

In this menu, while looking at information regarding digestive process, user can also hover to the teeth area to get information about teeth, as can be seen in Fig. 3 .

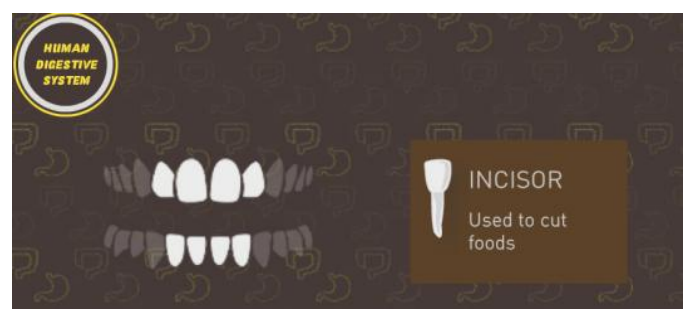

Figure 3. Hovering teeth will show information

The interface for this menu can be seen in Fig. 4. The Fig. 4 shows the interface for mechanical digestion.

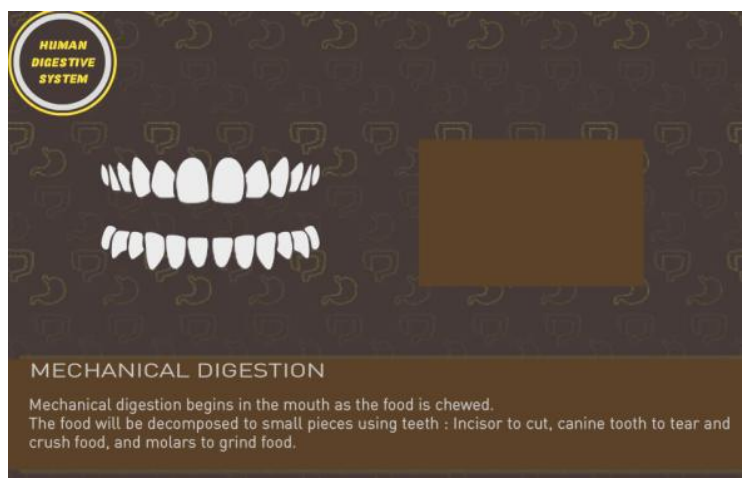

Figure 4. UI of teeth simulation

2) Oral cavity

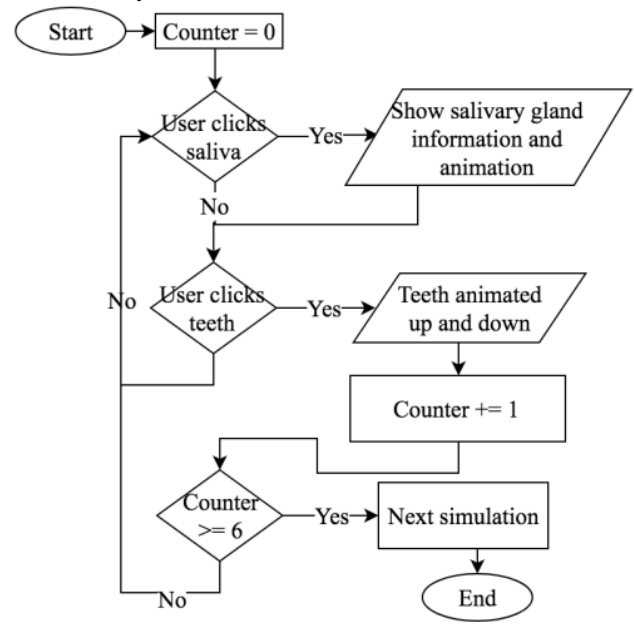

Figure 5. Process of oral cavity simulation 
During the chewing process using teeth, saliva will help as the lubricant, and also capable of breaking down starch into simpler sugars such as maltose and dextrin. In the application, user must click teeth several times to do the chewing process. Also, user can click the salivary gland to show the saliva moving around, and show the information. The process can be seen in Fig. 5. The interface can be seen in Fig. 6.

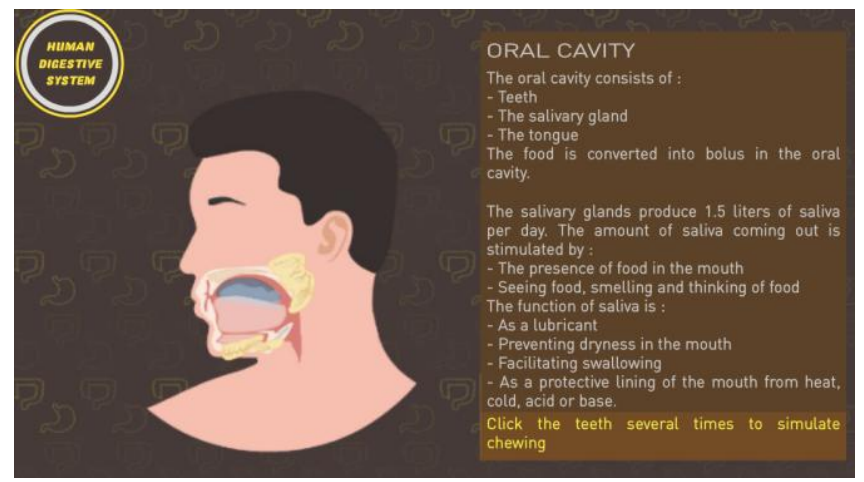

Figure 6. UI of oral cavity simulation

\section{3) Esophagus}

After passing through the mouth cavity, bolus (chewed food) goes into the esophagus. Currently the user is required to do swipe down gesture, so that the bolus can descend from esophagus to the stomach. When the user drag the bolus down, the throat area around the bolus performs a peristaltic motion that makes the bolus can move down. If the user moves the bolus too fast, then the bolus stops. The simulation on the esophagus lasts until the bolus reaches the end of the esophagus. The process can be seen in Fig. 7.

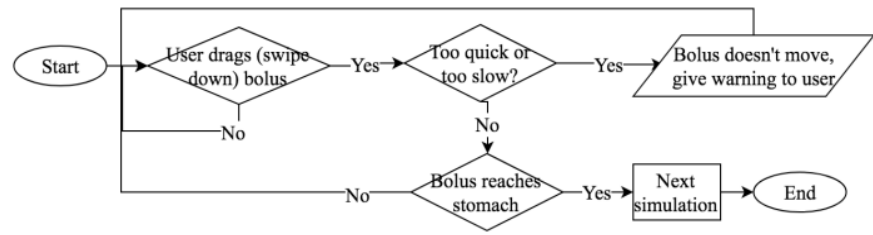

Figure 7. Process of esophagus simulation

The interface can be seen in Fig. 8 .

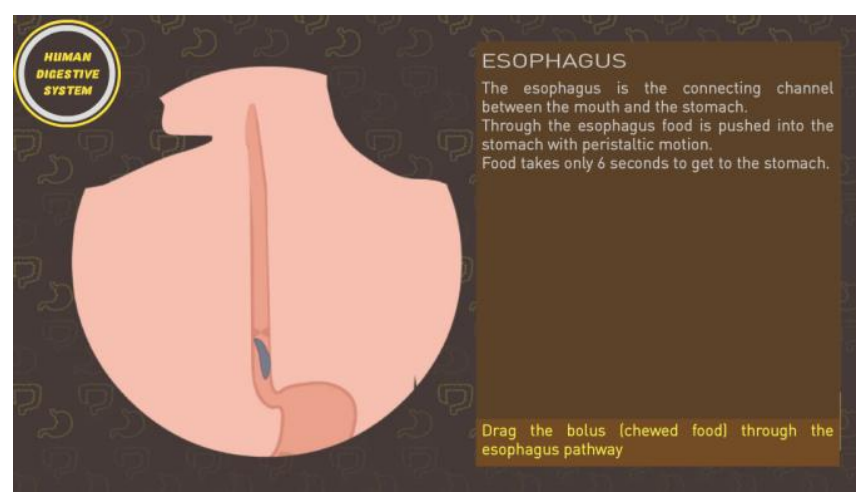

Figure 8. UI of esophagus simulation

\section{4) Stomach}

After passing through the esophagus, the bolus enters the stomach. In this gastric simulation, the user is required to press any key repeatedly on the keyboard to make the stomach do a movement of stirring food so that the food can be mixed with stomach acid perfectly as in Figure 10. While running this simulation, user can also hover to the gastric acid to show information. The simulation stopped when the food is mixed well. The process can be seen in Fig. 9.

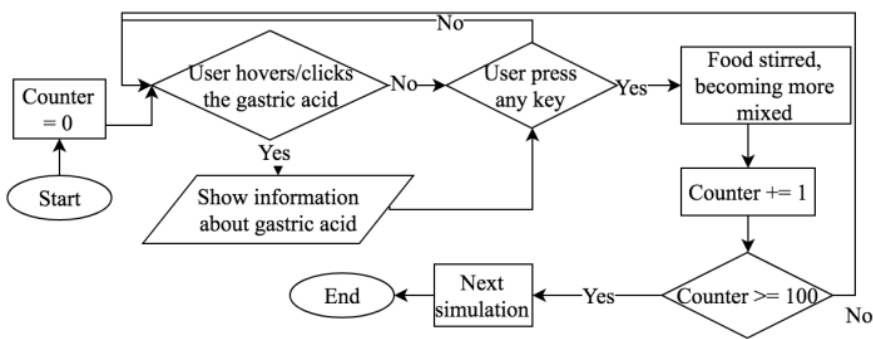

Figure 9. Process of stomach simulation

The interface can be seen in Fig. 10.

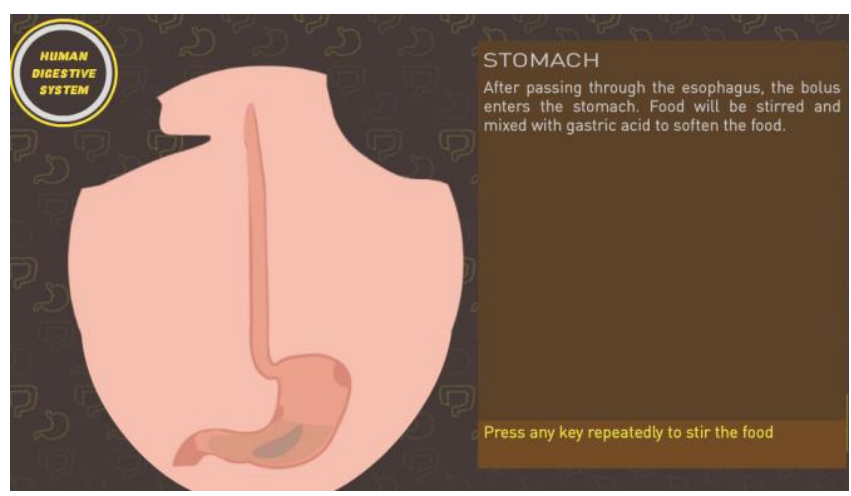

Figure 10. UI of stomach simulation

\section{5) Small Intestine}

The simulation of the small intestine explains how foods that have been processed from the stomach then enter the small intestine to take the juice of the food. Before the food is absorbed, the food is first mixed with bile from the liver and enzymes of the pancreas.

Users are asked to click on the pancreas organ to release the enzyme produced pancreas. After that the user is asked to click on the liver to release the bile acid. The process can be seen in Fig. 11.

In this small intestine simulation, the user can also hover the mouse on the villi section to get more details about the villi (finger-like projections that extend into the lumen of the small intestine). If food has been mixed with bile acid and digestive enzyme, then the food can be dragged (with mouse) through the small intestine. This simulation will end if the user moves food with the mouse following the pathway of the small intestine correctly. The interface can be seen in Fig. 12. 


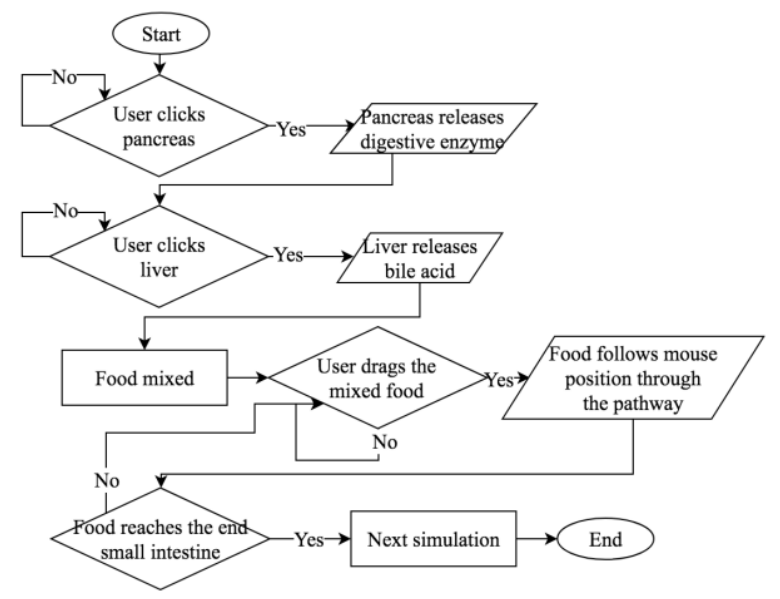

Figure 11. Process of small intestine simulation

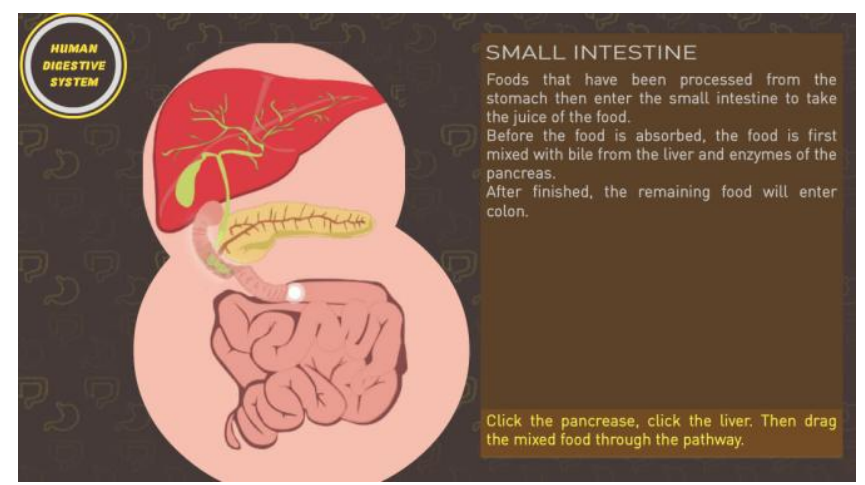

Figure 12. UI of small intestine simulation

\section{6) Large intestine}

After the juice of food is absorbed by the small intestine, the remaining of the food (indigestible food) enters the large intestine. In this large intestine simulation, the user is required to move the food through the large intestine.

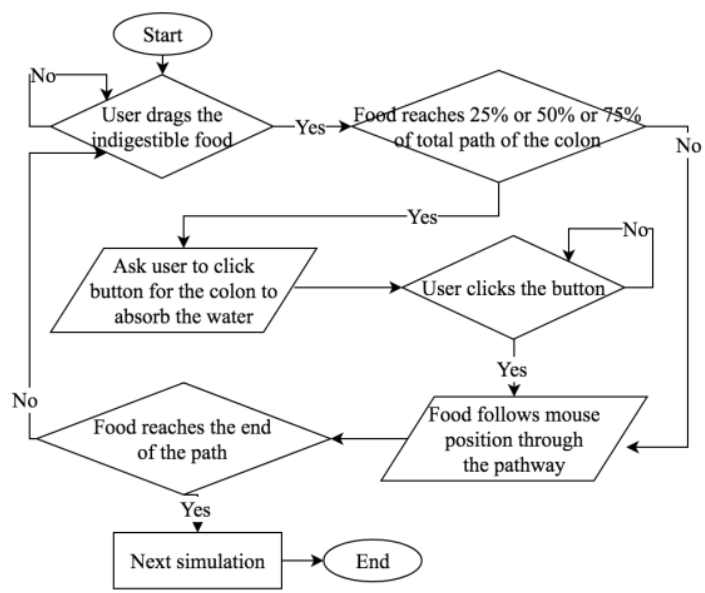

Figure 13. Process of large intestine simulation

Each time user moves the food, there are markers to show that the food is going to be absorbed by water content by the large intestine. Users are required to press a button for the large intestine to absorb water in the food. This simulation continues until the food reaches the end of the large intestine. The process can be seen in Fig. 13. The interface can be seen in Fig. 14.

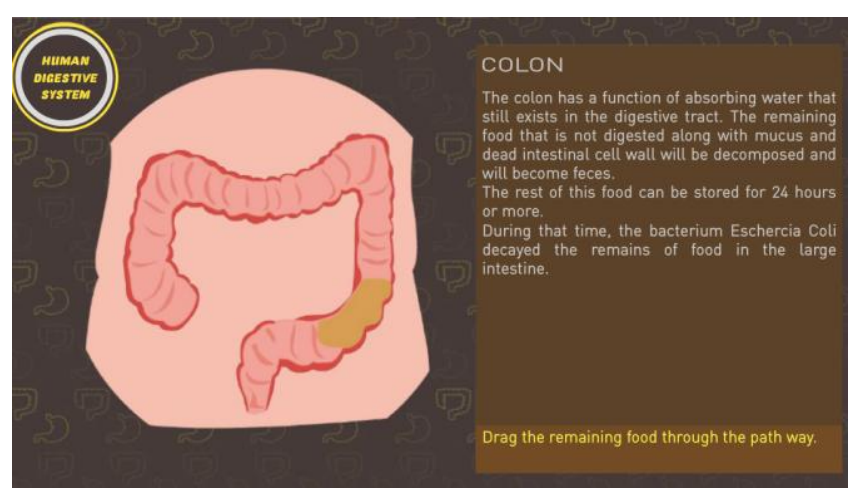

Figure 14. UI of large intestine simulation

7) Anus

After the food is decomposed in the large intestine and becoming feces, the feces enters the rectum and is stored until the feces passes through the anus.

In this anus simulation, the user is asked to press any key of the keyboard continuously until the width of the anus exceeds the width of the feces. When the width of the anus has exceeded the width of the feces then the feces can get out through the anus. After the feces out of the anal part, the human digestive simulation has ended and the program returns to the main menu. The process can be seen in Fig. 15.

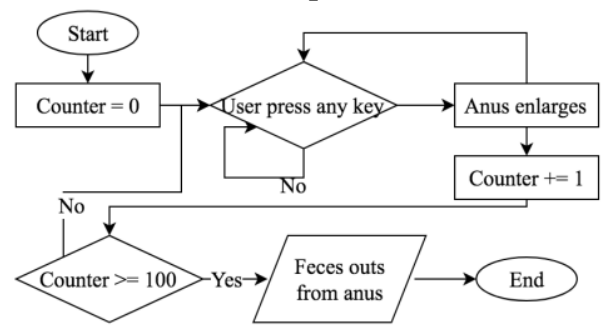

Figure 15. Process of anus simulation

The interface can be seen in Fig. 16.
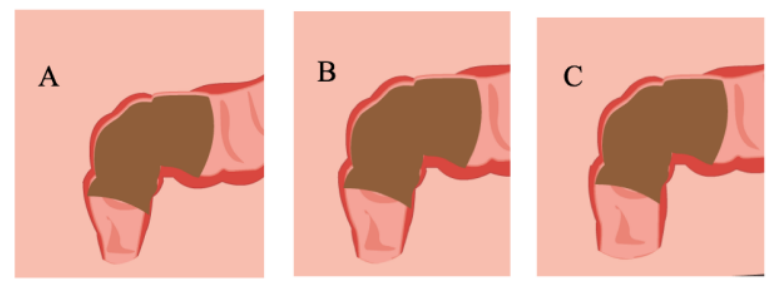

Figure 16. UI of anus simulation

\section{System Testing}

The application will be tested using 2 methods, questionnaire based for user feedback, and human-computer interaction test, to 10 respondents from senior high school. 


\section{A. User Feedback}

The respondents are given a questionnaire to be answered, the details can be seen in Table I.

TABLE I. USER FEEDBACK (QUESTIONNAIRE)

\begin{tabular}{lcccc}
\hline \multicolumn{1}{c}{ Aspect } & Very Less & Less & Good & Excellent \\
\hline Materials are good & $3.10 \%$ & $0.00 \%$ & $75.0 \%$ & $21.9 \%$ \\
Images are good & $3.10 \%$ & $0.00 \%$ & $65.6 \%$ & $31.3 \%$ \\
Animations are good & $3.10 \%$ & $3.10 \%$ & $65.6 \%$ & $28.1 \%$ \\
Colors match the game & $3.10 \%$ & $9.40 \%$ & $71.9 \%$ & $15.6 \%$ \\
Audio match the game & $3.10 \%$ & $0.00 \%$ & $75.0 \%$ & $21.9 \%$ \\
Clear language & $3.10 \%$ & $6.30 \%$ & $68.8 \%$ & $21.9 \%$ \\
Simulations are easy to & $3.10 \%$ & $0.00 \%$ & $84.4 \%$ & $12.5 \%$ \\
use and supports learning & & & & \\
\hline
\end{tabular}

\section{B. Human-Computer Interaction Test}

Five respondents are given the test to assess how well they can play the game, using the Human-Computer Interaction (HCI) test. The score will scale from 0 to 5 . The result can be seen in Table II.

TABLE II. HUMAN-COMPUTER INTERACTION TEST

\begin{tabular}{lccccccc}
\hline \multicolumn{1}{c}{ Aspect } & Person & Person & Person & Person & Person & \multirow{2}{*}{ Average } \\
& $\mathbf{1}$ & $\mathbf{2}$ & $\mathbf{3}$ & $\mathbf{4}$ & $\mathbf{5}$ & \\
\hline Time to Learn & 3 & 3 & 3 & 4 & 3 & $80 \%$ \\
$\begin{array}{l}\text { Speed of } \\
\text { Performance }\end{array}$ & 3 & 4 & 3 & 3 & 3 & $80 \%$ \\
$\begin{array}{l}\text { Error Rate } \\
\text { Retention over }\end{array}$ & 3 & 3 & 2 & 4 & 3 & $75 \%$ \\
$\begin{array}{l}\text { Time } \\
\begin{array}{l}\text { Subjective } \\
\text { satisfaction }\end{array}\end{array}$ & 4 & 3 & 4 & 3 & 3 & $85 \%$ \\
\hline
\end{tabular}

\section{CONCLUSION}

Based on the test results can be concluded several things as follows:

- Every animation on the disease menu, digestive simulation, and tests have been well implemented and able to support the learning process.

- Material, images, language that clearly support the learning media well with the percentage of the total good and excellent $96.9 \%$ in the user feedback test.

- The simulation can support the learning process of digestive system, with $84.4 \%$ of users answered good in the feedback test.

- Based on the human-computer interaction test, the UI of the application and the performance is good, with the average of $81 \%$ score in the whole $\mathrm{HCI}$ test.

\section{REFERENCES}

[1] F. Kong and R.P. Singh. "Disintegration of Solid Foods in Human Stomach,” J. Food Science, vol. 73, no. 5, pp. R67-R80, Jun. 2008 doi: 10.1111/j.1750-3841.2008.00766.x.

[2] S. Bassett, "The Digestive System," PowerPoint Lecture Presentations for Human Anatomy, Pearson Education, 2012.

[3] O.O. Jethro, A.M. Grace, and A.K. Thomas, "E-Learning and Its Effects on Teaching and Learning in a Global Age." Int. J. Academic Research in Business and Social Sciences, vol. 2, no. 1, pp. 203-210, Jan. 2012.

[4] S.E. Smaldino, D.L. Lowther and J.D. Russell, Instructional Technology and Media for Learning, 9th ed., Prentice Hall, 2008. 